\title{
Growing Our Commitment to Promoting Fruits and Vegetables: Looking Beyond the International Year of Fruits and Vegetables 2021
}

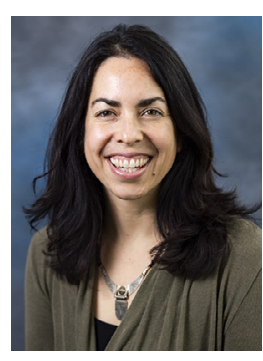

Andrea Bersamin
Despite the essential benefits of fruits and vegetables (F\&V), much of the world does not eat the minimum recommended amounts. In addition, nearly $50 \%$ of all F\&V produced globally is wasted between harvest and consumption. ${ }^{1}$ These issues put unnecessary pressures on both the health of the people and the planet. ${ }^{1}$ In recognition of the critical role F\&Vs play in promoting both healthy diets and sustainable food systems, the United Nations declared 2021 as the International Year of Fruits and Vegetables (IYFV 2021). ${ }^{2}$

As we approach the end of this celebration, we call on nutrition educators to continue and extend this important work beyond the IYFV 2021 through nutrition education actions that promote (1) advocacy and awareness raising, (2) knowledge creation and dissemination, (3) policy making, and (4) capacity development and education. ${ }^{2}$

\section{ADVOCACY AND AWARENESS RAISING}

Transformative approaches for better F\&V production and consumption starts with all of us advocating for systemic change. Let's reach into our toolkit that includes a wide assortment of advocacy and awarenessraising tools from which to choose: 5-A-Day campaigns, webinars or virtual events related to $F \& V$, and other fresh approaches such as cooking demonstrations, recipes contests, and exhibitions of local F\&Vs in farm-to-school programs. ${ }^{2-4}$

\section{KNOWLEDGE CREATION AND DISSEMINATION}

As nutrition educators, we play a vital role in building a strong evidence-base on the nutritional, health, and environmental benefits of the various components of $F \& V$ food systems, from production to consumption. We also play an important role in developing, validating, and promoting tools to measure $\mathrm{F} \& \mathrm{~V}$ intake that are essential to monitoring progress toward reaching $\mathrm{F} \& \mathrm{~V}$ consumption recommendations. By creatively varying our dissemination and implementation toolkit, findings are better translated into practice. ${ }^{2}$

\section{POLICY MAKING}

Evidence-informed policies that promote appropriate investments, partnerships, and holistic approaches to enhance F\&V access and intake and reduce waste in a range of settings from schools to food pantries to hospitals can have a significant and sustained impact, especially now within the context of COVID-19. As nutrition educators, we can sensitize policy makers on the need for these synergistic policies. Schoolbased nutrition policies in support of $\mathrm{F} \& \mathrm{~V}$, for example, should be comprehensive enough to promote the availability and access to locally grown $\mathrm{F} \& \mathrm{~V}$ and school gardens, as well as the fruitful integration of gastronomy or quality food education initiatives. These types of policy actions can increase children's F\&V intake while simultaneously reducing food waste in national school meals programs. $^{2,4-5}$

\section{CAPACITY DEVELOPMENT AND EDUCATION}

A systematic approach to capacity development and education can amplify the impact we have as nutrition educators on increasing awareness, generating knowledge, and influencing policies around $F \& V$ food systems. Our reach should extend to producers, children, families, communities, and policy makers from multiple sectors. Only through meaningful engagement with a range of actors along the F\&V food system can we make impactful progress toward the 2030 Global Development goals. ${ }^{2-6}$

SNEB Division of International Nutrition Education (DINE) Andrea Bersamin

Center for Alaska Native Health Research, University of Alaska Fairbanks

Yenory Hernández-Garbanzo

Food and Agriculture Organization of the United Nations

Abiodun T. Atoloye

Uconn Rudd Center for Food Policy and Obesity, University of Connecticut

Jorge U. Gonzalez

Food and Agriculture Organization of the United Nations

Israel Ríos-Castillo

Food and Agriculture Organization of the United Nations

Thu Thu May Oo

Teachers College, Columbia University Jinan Banna

Department of Human Nutrition, Food and Animal Sciences, University of Hawaii Manoa

Ahlam El Shikieri

College of Applied Medical Sciences, Department of Clinical Nutrition, Taibah University Eunice Bonsi

Department of Food and Nutritional Sciences, CAENS, Tuskegee University 


\section{REFERENCES}

1. Food and Agriculture Organization of the United Nations. Fruit and Vegetables - Your Dietary Essentials. The International Year of Fruits and Vegetables, 2021, Background Paper. FAO; 2020.

2. Food and Agriculture Organization of the United Nations. International Year of Fruits and Vegetables 2021 Global Action Plan. FAO; 2021.
3. Food and Agriculture Organization of the United Nations. Los Mercados Mayoristas. Abastecimiento de Alimentos Saludables: Gestión y Desafios ante el COVID19. FAO; 2021.

4. Gerritsen S, Barquera S, Wolfenden L. The Effectiveness of Policies and Programmes Promoting Fruits and Vegetables - Background Paper for the FAO/WHO International Workshop on FEV 2020. FAO; 2021.
5. Sternadt D, Mellado JP, Rivas-Mariño G, Moyano D. Alimentación Sabrosa y sin Desperdicios: La Alternativa Para Mejorar el uso de los Recursos Públicos en los Programas de Alimentación Escolar en AméRica Latina y el Caribe. FAO; 2021.

6. Darfour-Oduro SA, Andrade JE, Grigsby-Toussaint DS. Review of policies to increase fruit and vegetable consumption and physical activity in 49 low- and middle-income countries. $J$ Public Health. 2018;41:119-129. 